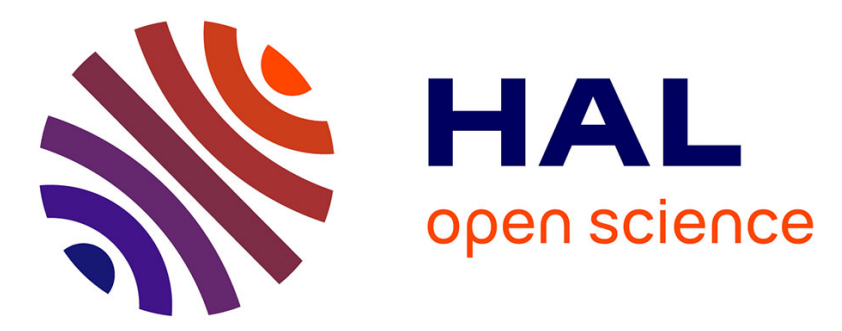

\title{
Alkylsquarates as key intermediates for the rapid preparation of original drug-inspired compounds.
}

Julie Charton, Lise Charruault, Rebecca Déprez-Poulain, Benoit Déprez

\section{To cite this version:}

Julie Charton, Lise Charruault, Rebecca Déprez-Poulain, Benoit Déprez. Alkylsquarates as key intermediates for the rapid preparation of original drug-inspired compounds.. Combinatorial Chemistry and High Throughput Screening, 2008, 11 (4), pp.294-303. 10.2174/138620708784246013 . inserm00281198

\section{HAL Id: inserm-00281198 https://www.hal.inserm.fr/inserm-00281198}

Submitted on 21 May 2008

HAL is a multi-disciplinary open access archive for the deposit and dissemination of scientific research documents, whether they are published or not. The documents may come from teaching and research institutions in France or abroad, or from public or private research centers.
L'archive ouverte pluridisciplinaire HAL, est destinée au dépôt et à la diffusion de documents scientifiques de niveau recherche, publiés ou non, émanant des établissements d'enseignement et de recherche français ou étrangers, des laboratoires publics ou privés. 


\section{Alkylsquarates as key intermediates for the rapid preparation of original drug-inspired compounds.}

Julie Charton, ${ }^{a, b, c}$ Lise Charruault, ${ }^{a, b, c}$ Rebecca Deprez-Poulain, ${ }^{a, b, c}$ Benoit Deprez. $a, b, c$

aINSERM U761 Biostructures and Drug Discovery, Lille F-59006, France

${ }^{b}$ Faculté de Pharmacie, Université Lille 2, Lille F-59006, France

'Institut Pasteur de Lille, Lille F-59000, France

Corresponding author: Address: 3 rue du Pr. Laguesse, 59006 Lille

Cedex, France. Tel.: +33 320964 948; fax: +33 320964 709; e-mail:

julie.charton@univ-lille2.fr 
Abstract: Many natural privileged scaffolds contain a basic nitrogen atom, which often is a key element of pharmacophore and a chemically reactive centre as well. In our ongoing research program devoted to the design of targeted libraries based on acidic templates, we develop methods to convert privileged basic compounds -like natural alkaloids or drugs- into acidic compounds. This conversion leads to a profound alteration of the pharmacophore, without changing the overall shape and lipophilicity of the molecule. We expect such modifications to generate unexpected biological activities. Recently, we focused on derivatives of squaric acid, a vinylogous carboxylic acid. Two series were studied. First we describe a new, selective parallel synthesis of squaramic acids from a dissymmetric diester (3-tert-butoxy-4-ethoxycyclobut-3-en-1,2-dione). This efficient procedure avoids the synthesis of the undesired squaramides. Secondly we describe a microplate parallel synthesis

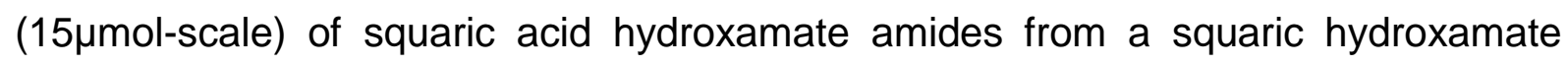
ester. 


\section{Introduction}

\section{Privileged structures.}

The construction of a library of "biologically" competent compounds is a cornerstone of HTS-based lead discovery. Recognition of frequently active templates (natural or synthetic) and published data on side-effects of known drugs provides guidelines for the selection of compounds.[1] In 1988, Evans introduced the concept of "privileged structure" to account for the outstanding recurrence of some scaffolds, such as benzodiazepines, in the world of bioactive compounds. Since then, numerous teams have focused on their use in medicinal chemistry.[2-5] More recently, IUPAC has given a structural definition that corresponds to the common denominator of Evans' privileged structures.[3] According to that definition a privileged structure is substructure "that often consists of a semi-rigid scaffold, which is able to present multiple hydrophobic residues without undergoing hydrophobic collapse".[4] This definition is useful for the construction of screening library because it offers selection criterias independent of any established biological activity. We ourselves have developed series of bio-inspired privileged structures: "spiro-compounds" and tropane-based compounds.[5-6] Among privileged structures that are also found in natural compounds, piperidine and piperazine in one hand, and phenethylamine, tryptamine, histamine derivatives (cyclized or not) in the other hand, are interesting because they contain a basic nitrogen atom'.[7]

\section{Drug-morphing and combinatorial synthesis of privileged structures}

We have been interested into drug-morphing, i.e. transforming biologically active compounds on a target to related compounds active on new targets, by changes in pharmacophore. Wermuth and coll. have applied this concept to commercially available drugs and name it the "SOSA-Approach".[8] We intend to modify the amine function of privileged compounds into new pharmacophores by simple chemical reactions. Recently, we focused on squaric acid as a key chemical intermediate that could serve the design of chemical libraries for screening. We use privileged bioinspired amines and transform them into squaric acid derivatives. In particular, we

\footnotetext{
${ }^{i}$ For examples, see catalogs of building-blocks providers like ChemFiles ${ }^{\circledR}$ from Sigma-Aldrich.Inc or Optimer-Building Blocks ${ }^{\circledR}$ from Array biopharma.
} 
aimed at addressing two key problems encountered in medicinal chemistry (Figure 1). First, these compounds can palliate the shortage of acidic compounds in screening libraries. Indeed, squaramic acid and squaric acid $\mathrm{N}$-hydroxylamide amide derivatives are monobasic acid with pKa of 2-3 [9] and 8-9ii respectively. Secondly, these compounds display new chelating zing-binding groups (ZBGs) that are highly desirable in medicinal chemistry.

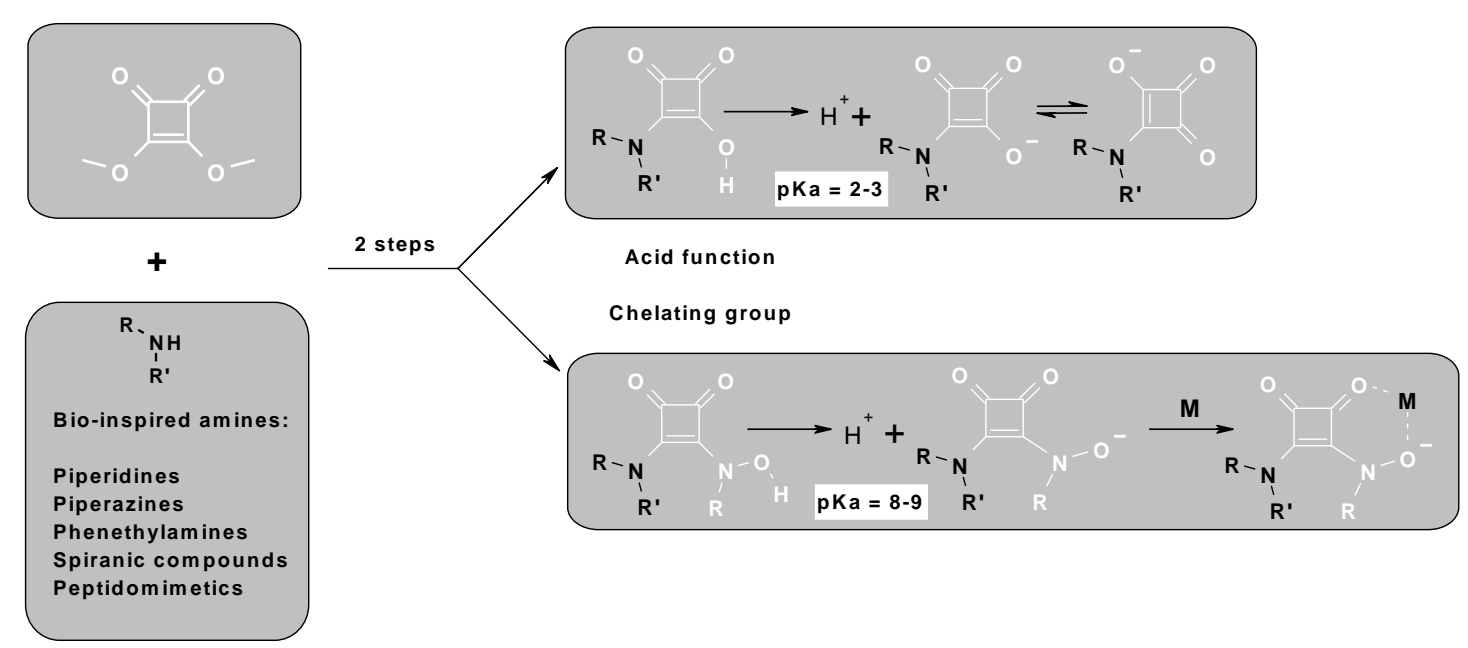

Figure 1: Examples of bio-inspired libraries of squaramic acids and squaric acid $\mathrm{N}$ hydroxylamide amides

\section{Squaric acid in medicinal chemistry}

Squaric acid is a diacid that exhibits two acidic hydroxyl groups with pKa values of 0.54 and 3.48 as well as two highly polarized carbonyl groups.[10] This unique structure provides not only versatile proton acceptor sites [11] at the carbonyl function for hydrogen bonding but also binding sites to metal ions.[12,13] Since the pioneering work of Cohen [14] in 1959, many examples of the use of squaric template (Figure 2) have already been described particularly in the fields of bioorganic and medicinal chemistry.[15]

\footnotetext{
ii pKa of a prototypal compound was determined in DMSO/H2O (58/42) by potentiometric titration using $0.025 \mathrm{M} \mathrm{NaOH}$.
} 


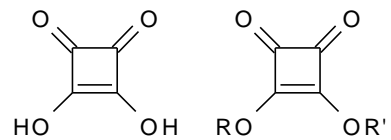

squaric acid

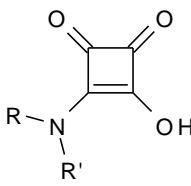

squaramic acid

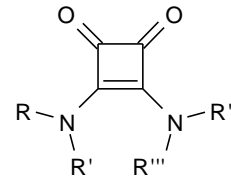

squaramide

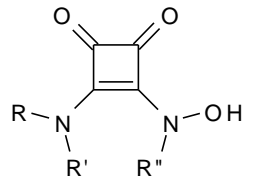

squaric acid

$\mathrm{N}$-hydroxylamide amide

Figure 2. Nomenclature of squaric derivatives

The conjugate base of squaric acid can serve as a mimic of negatively charged groups that are common in biology such as carboxylates and phosphate mono- and diester. As a result, derivatives of squaric acid have been used as a replacement for these groups in medicinal applications. Sekine and co-workers have used a diamide of squaric acid as a replacement for one of the phosphate diester linkages in an oligodeoxynucleotide.[16] Squaric acid unit were also incorporated by Hanessian et al. in analogues of SAHA (Suberoyl Anilide Hydroxamic Acid, vorinostat).[17] Ishida et al. described the synthesis of amino-acid analogues bearing a squaryl group as a carboxylic acid surrogate.[18] Kinney and co-workers have reported the use of 3,4diamino-3-cyclobutene-1,2-dione as a replacement group for the entire a-amino carboxylic acid functionality in various NMDA (N-methyl-D-aspartic acid) antagonists.[19] They also achieved the synthesis of C-linked squarate anologues of glycine, $\beta$-alanine and $\gamma$-aminobutyric acid.[20] Xie et al. demonstrated that squaric acid is an effective pharmacophore for the design of Tyrosin phosphatase inhibitors.[21]

Lee and co-workers have used a squaryldiamide as a new bioisostere of unsubstituted guanidine in the synthesis of peptidomimetic inhibitors of HIV-1 TatTAR interactions.[22] Diaminocyclobutenedione template was also used for bioisosteric replacement of the $\mathrm{N}$-cyanoguanidine moiety of pinacidil and afforded a prototype for a novel series of $\mathrm{K}_{\mathrm{ATP}}$ channel openers.[23]. Recently, a novel series of cyclobutenedione centered C(4)-alkyl substituted furanyl analogs was developed as potent CXCR2 and CXCR1 antagonists.[24] (Figure 3) 


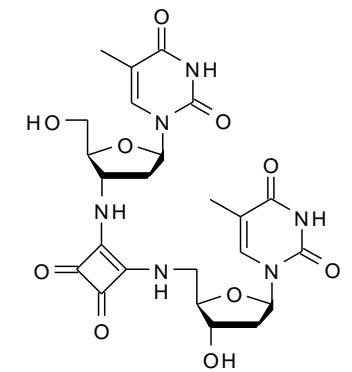

Oligodeoxynucleotide analog containing squaryl group as mimic of phosphate group Sato et al.

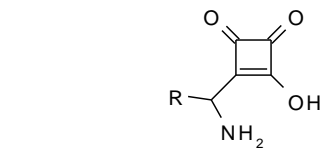

Novel aminosquaric acids Ishida et al.

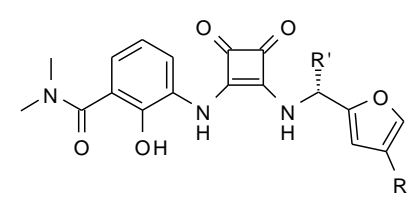

CXCR2-CXCR1 dual inhibitors Chao et al.

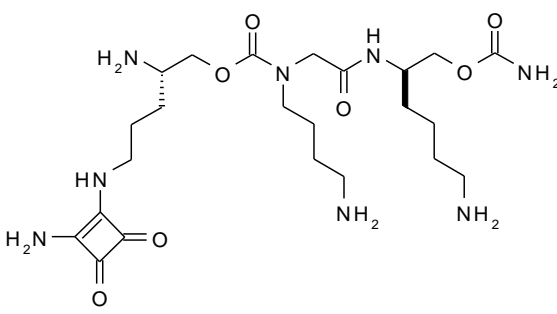

Peptidomimetic inhibitors of HIV-1 Tat-TAR interaction Lee et al.

Figure 3. Examples of bioactive compounds displaying a squaric template.

Thus in the view of this growing interest of medicinal chemists in the use of squaric acid either as a linker, or as a precursor of acidic or metal binding functions, we tried to develop efficient parallel synthesis procedures for the incorporation of this structure into potentially bioactive compounds.

\section{Converting basic compounds to acidic compounds}

\section{Evidencing the lack of acidic structures in screening libraries.}

Among commercially available drugs, one can notice that acidic functions are essential for several important therapeutic classes like NSAIDs (Non Steroidal AntiInflammatory Drugs), sartans and glitazones (Figure 4). Interestingly, these drugs target very different protein classes: enzymes, GPCRs (G-protein coupled receptors) and nuclear hormone receptors. Carboxylic acid and bioisosters are thus important pharmacophoric groups. In agreement with this observation, Fesik et al identified carboxylic acid as a privileged structure using screening by NMR.[25]
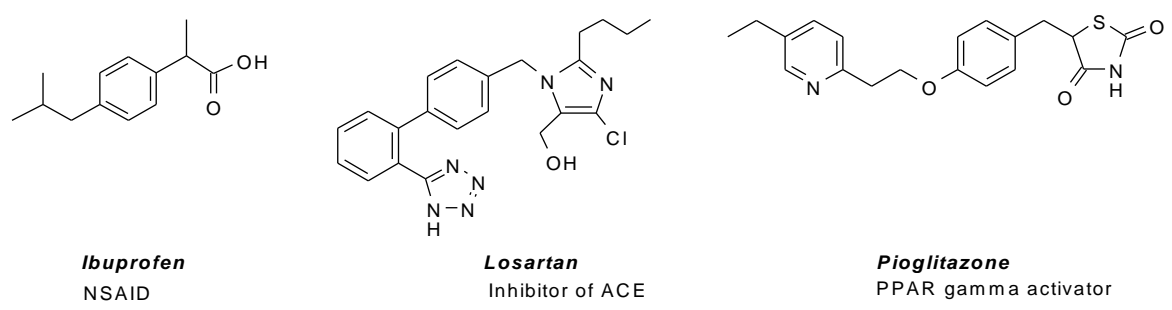

Figure 4. Examples of structures of acidic drug molecules. 
However, a survey of $\mathrm{MDL} \circledast \mathrm{CMC}$ database reveals that acidic compounds are underrepresented in the chemical space of bioactive molecules as shown in Figure 5. iii The same trend can be observed when analyzing the MDL® Drug Data Report. Indeed, among compounds in clinical phase or launched on the market, charge at $\mathrm{pH}$ 7.4 which reflects the acidic or basic behaviour of compounds is not evenly

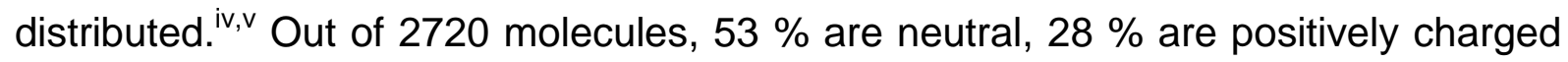
and only $19 \%$ are negatively charged.

Since the beginning of high-throughput screening for lead discovery, the number of providers of chemical libraries has considerably increased. These libraries reflect either the history of the provider's sources and/or the ease of synthesis of compounds. Recently, the concept of targeted libraries has emerged to fill the diversity gaps. An analysis of databases of several chemical library providers reveals that libraries for High-Throughput Screening lack acidic compounds (Figure 5). ${ }^{\text {vi }}$ Thus, the relative lack of acidic compounds in bioactive molecules may only reflect the lack of acidic molecules available for screening and the relative difficulty of synthesis of such compounds.

\footnotetext{
iii For this study, 893 compounds for which 1219 pKa values were available in the database were used. The MDL ${ }^{\circledR}$ Comprehensive Medicinal Chemistry (CMC-3D) database is an electronic version of Volume 6 of Comprehensive Medicinal Chemistry, published by Pergamon Press in March 1990. CMC-3D has been updated to include recently approved or registered drugs. Total number of compounds is 8000 .

iv The MDL Drug Data Report (MDDR) database is an online version of the Drug Data Report journal by Prous Science Publishers.

$\checkmark$ Ionization was performed using pKa value calculation of PipelinePilot TM V 6.0.2 from Scitegic.Inc

vi Libraries analyzed were AsinexTM(Gold) and ChembridgeTM.
} 


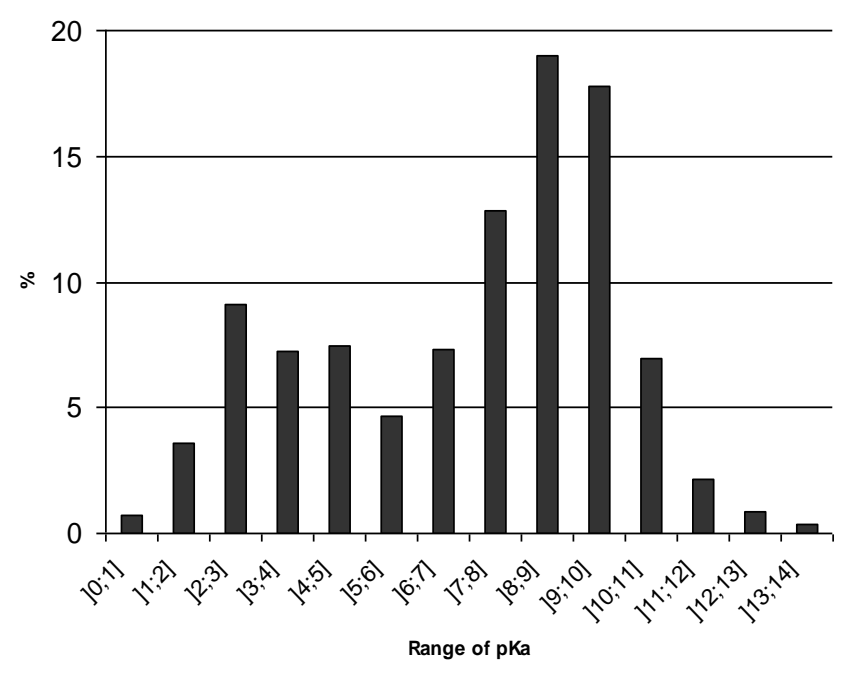

A: Percent of compounds of MDL CMC $^{\mathrm{TM}}$ database that have $\mathrm{pKa}(\mathrm{s})$ in the corresponding range

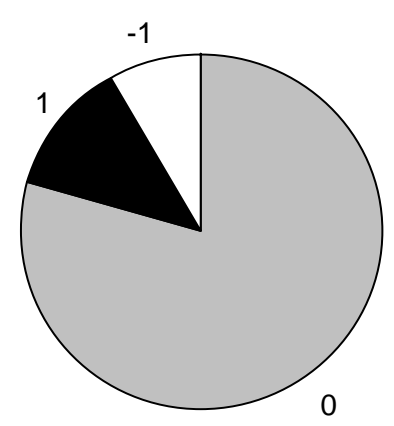

B: Charge of compounds at pH 7.4 : a survey of two different providers of chemical compounds (total of compounds : 602717)

Figure 5. Evidencing the lack of acidic structures in bioactive compounds $(A)$ and in chemical libraries (B). vii

We have been interested in the past few years in synthesizing acidic privileged structures. We focused on acidic heterocycles and hydroxamic acids, in order to supply our in-house collection with acidic compounds. [26-27] We now focus on squaric acid derivatives and are interested in incorporating squaric moiety in small lead- or drug-like molecules using a simple chemical group transformation for the conversion of rather common secondary or primary amines into a less common acidic group.

\section{A simple procedure to convert drug-like amines into acidic compounds}

\section{a-Parallel synthesis}

Squaric scaffold was introduced using a dissymmetric diester: 3-tert-butoxy-4-ethoxycyclobut-3-en-1,2-dione 1, readily obtained from commercially available diethyl squarate (Scheme 1). The use of this intermediate avoids the formation of symmetrical squaramides resulting from a double substitution reaction by the

\footnotetext{
vii When comparing graph $A$ and $B$ one must take into account that the bars on the left side of graph $A$ contain weak bases not protonated at $\mathrm{pH} 7.4$ (like pyridine : charge $=0$ ) and weak acids deprotonated at $\mathrm{pH} 7.4$ (like carboxylic acids : charge $=-1$ ). Likewise, the bars on the right side of graph A contains weak bases protonated at $\mathrm{pH} 7.4$ (like alkylamines : charge $=+1$ ) and weak acids not deprotonated at $\mathrm{pH} 7.4$ (like phenols : charge $=0$ ).
} 
amine.[28] Compound 1 reacted with a selection of secondary amines to provide tertbutyl squaramates in excellent purity without any chromatography. A final step of tertbutyl deprotection afforded the resulting squaramic acids.
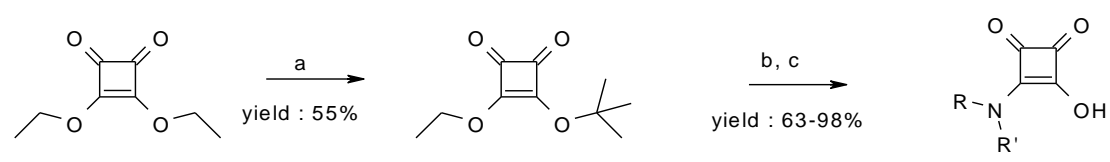

$2 a-j$

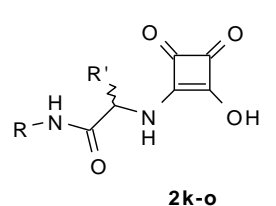

Scheme 1. Reaction conditions : a. t-BuOK, $1 \mathrm{M}$ in THF (1eq.), THF, $4^{\circ} \mathrm{C}$; b. RR'NH, $\mathrm{NEt}_{3}$, EtOH, r.t.; c. TFA/dichloromethane $(1 / 1 \mathrm{v} / \mathrm{v}), 4^{\circ} \mathrm{C}$.

\section{b-Choice of amines}

Natural scaffolds may interact with multiple biological targets and can be regarded as embodying privileged structures. Many synthetic templates now considered as privileged structures derive from natural compounds. For example as far as nitrogenheterocycles are concerned, piperidine and piperazine are heterocycles that are very frequent substructures in natural alkaloids [29] benzylpiperidines and spirocyclic compounds are also constrained analogues of endogenous bioactive monamines (adrenaline, dopamine, tryptamine, histamine,...) that target GPCRs.[30-31] Diphenylmethyl, benzimidazole are other privileged structures found in natural compounds. [25] Taking all this into account, many natural products have given birth to ready-to-use building-blocks. [32] Figure 6 gathers all the selected structures that were incorporated for validation of our synthetic procedure. Amine building-blocks a-e contain a piperidine ring. Amines $\mathbf{f}-\mathbf{h}$ display a piperazine moiety. Amines $\mathbf{i}-\mathbf{j}$ as well as a-e can be considered as analogues of endogenous mono-amines. Compounds $\mathbf{f}, \mathbf{i}$ and $\mathbf{n}$ contain biphenylmethyl rings. Benzimidazole and its benzotriazole are represented respectively in compounds $\mathbf{b}$ and $\mathbf{c}$. Finally, peptidomimetics derived from Boc-phenylalanine or Boc-leucine were used (k-o).

Figure 6: Bio-inspired secondary amines and peptidomimetic primary amines 


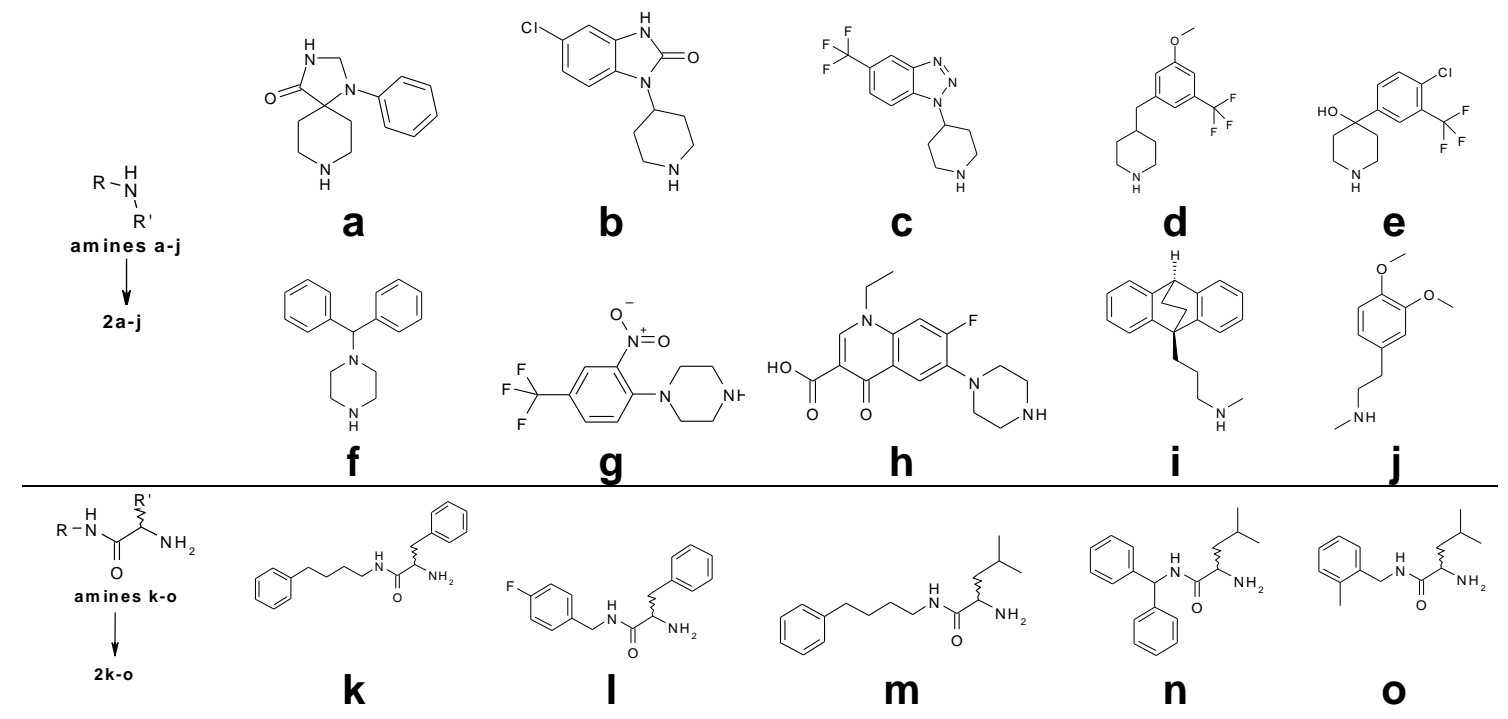

Results observed for the conversion of the set of secondary amines into squaramic acids are compiled in Table1.

Piperidines were successfully converted into squaric amides (Table 1, 2a-2e). The reaction was selective and amide functionalities did not react with the squaric ester (compounds 2a-2b). Trifluoro-methyl derivatives afforded squaramic acid with good to excellent yields (compounds $\mathbf{2 c - 2 d}$ ) and the presence of a potentially reactive alcohol was well tolerated (compound 2e). Efficient reaction also occurred with piperazines diversely substituted in position 4 (Table 1, 2f-2h). Diphenylmethyl piperazine was successfully converted into squaramic acid 2f. $\mathrm{N}$-(2-nitro-4trifluoromethylphenyl) piperazine was also an excellent substrate (compound $\mathbf{2 g}$ ). The reaction of norfloxacin proceeded with good yield (compound $\mathbf{2 h}$ ) and resulted in a complete change of the pharmacophore of this potent antibiotic. The same observation was made on the antidepressant maprotiline, that was converted with good yield into the corresponding squaramic acid (compound 2i). The squaric derivative of 2,4-dimethoxy- $\mathrm{N}$-methylphenethylamine (compound 2j) was obtained with a medium yield of $63 \%$, since the protected intermediate was an oil that proved to be difficult to handle. The lower yields (below $80 \%$ ) obtained for some compounds (2a; $\mathbf{e}$; $2 \mathbf{g} ; \mathbf{2 h}$ ) were due to the more difficult substitution of squaric ester by the amine that eventually required to heat the reaction mixture and/or to add more equivalents of triethylamine. Tert-butyle deprotection was in all cases quantitative. 
Table 1. Conversion of secondary amines to squaramic acids

\begin{tabular}{cc|cc}
\hline Product & $\begin{array}{c}\text { Yield (\%) } \\
\text { (2 steps) }\end{array}$ & Product & $\begin{array}{c}\text { Yield (\%) } \\
\text { (2 steps) }\end{array}$ \\
\hline $\mathbf{2 a}$ & 79 & $\mathbf{2 f}$ & 92 \\
$\mathbf{2 b}$ & 91 & $\mathbf{2 g}$ & 74 \\
$\mathbf{2 c}$ & 85 & $\mathbf{2 h}$ & 77 \\
$\mathbf{2 d}$ & 98 & $\mathbf{2 i}$ & 86 \\
$\mathbf{2 e}$ & 76 & $\mathbf{2 j}$ & 63 \\
\hline
\end{tabular}

The scope of this efficient procedure for preparation of squaramic acids was extended to the synthesis of some squaric peptidomimetic derivatives isolated with excellent yields (Table2).

Table 2. Preparation of squaric peptidomimetics

\begin{tabular}{cc}
\hline Product & $\begin{array}{c}\text { Yield (\%) } \\
\text { (2 steps) }\end{array}$ \\
\hline $\mathbf{2 k}$ & 81 \\
$\mathbf{2}$ & 85 \\
$\mathbf{2}$ & 93 \\
$\mathbf{2 n}$ & 94 \\
$\mathbf{2 0}$ & 90 \\
\hline
\end{tabular}

\section{Converting basic compounds to zinc chelating compounds}

\section{Evidencing the need for new Zinc-Binding Groups (ZBG)}

Since long, $\mathrm{Zn}$ metallohydrolases have interested the medicinal chemistry community. They are important biological targets for drugs on the market or in clinical trials, such as inhibitors of angiotensin-converting enzyme carbonic anhydrase or more recently Histone Desacetylase [33-34-35] (Figure 7).

When targeting metalloproteases, a ZBG is necessary to bind to the Zinc ion (Figure 8) and sets the rest of the molecule in the active site. Using hydroxamate is convenient to achieve good activity at the screening stage because this function is one of the best $\mathrm{Zn}$ ligand. Nevertheless, a high binding to the target can be achieved with a "softer" ZBG, provided that the rest of the molecule fits nicely in the binding pocket (Figure 8).[36] Furthermore, because hydroxamic acids are often poorly 
absorbed and are prone to metabolic degradation and glucuronidation, there has been considerable interest in discovering alternative groups that can be incorporated in the structures of metalloproteases inhibitors.[37] The search of relevant new zing binding groups is widely investigated. ZBG can be classified in two classes as shown in Figure 9: 1) monodentate that include thiols, carboxylic acids, acidic heterocycles, phosphinic acids...2) bidentate that include hydroxamate and hydroxypyridones recently published ZBG of Cohen et al. [38-39] Recent examples of the use of heterocyclic ZBGs include hydantoines, triazolones and imidazolones as inhibitors of TACE (TNF-alpha converting enzyme) or tetrazoles as inhibitors of metallo- $\beta$ lactamase.[40-41]

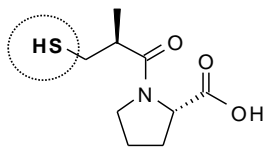

Captopril ACE

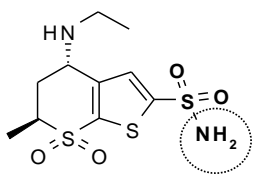

Dorzolamide

AN

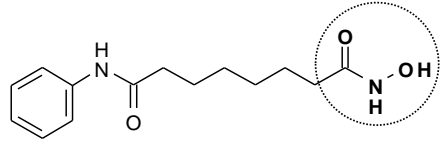

SAHA

HDAC

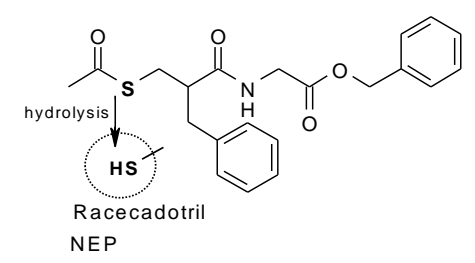

NEP

Figure 7: Examples of inhibitors of Zinc hydrolases on the market (each ZBG is circled)

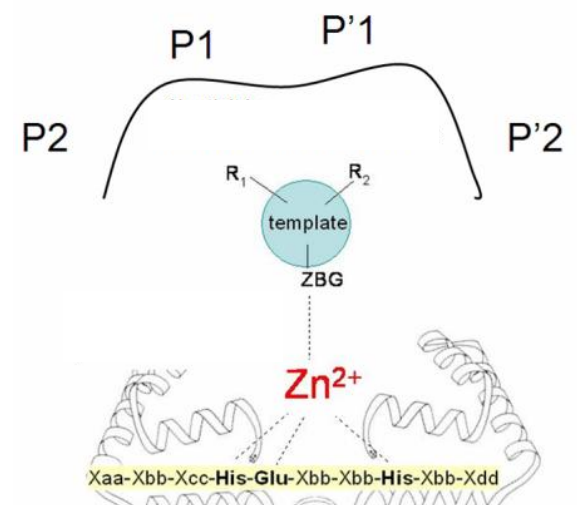

Figure 8: Orientating role of the $\mathrm{Zn}$ ion in the catalytic site of $\mathrm{Zn}$ metallo proteases. 


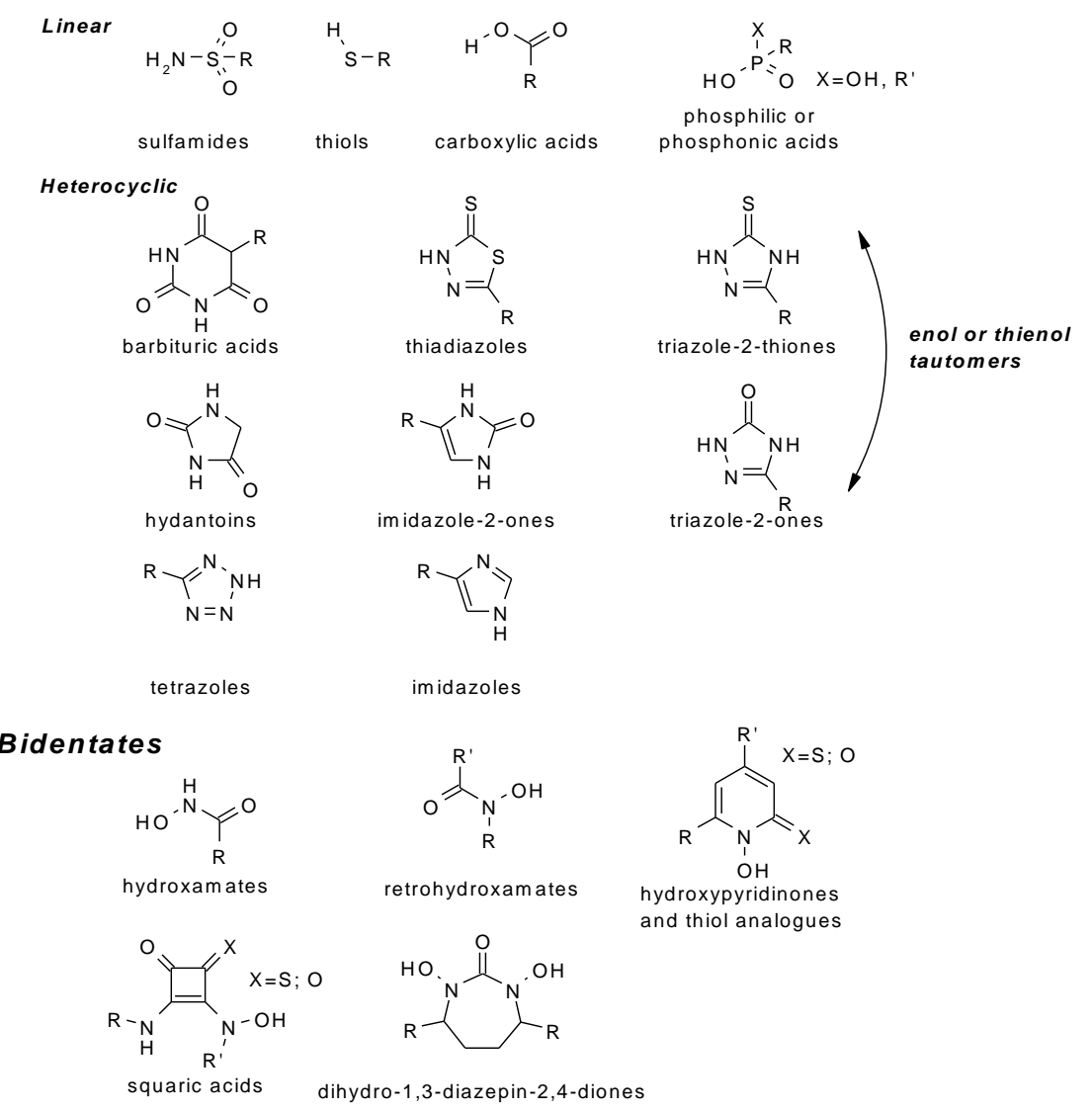

Figure 9: Classical and non-classical ZBGs classified by the Zinc-binding mode.

\section{Selection of squaric Acid $\mathrm{N}$-hydroxylamines template as Zn-chelating moiety.}

Brucker and co-workers have demonstrated that vinylogous hydroxamic acids derived from squaric acids are good metal chelators (Figure 10) and squaric acidbased inhibitors of matrix metalloproteases were reported.[15a,42] Hanessian et al. also replaced the hydroxamic acid of SAHA by squaric acid and squaric hydroxamic acid.[17] In both cases (HDAC or MMP inhibitors) no inhibitory activity was observed below $1.0 \mu \mathrm{M}$ and it was not clear wether the spatial requirements could be satisfied in the active sites of these enzymes. ${ }^{\text {viii }}$ The squaric/hydroxamic acid hybrids are generally not as potent as hydroxamic acid-based inhibitors, many of which have inhibition constants in the $\mathrm{nM}$ range but these hybrids nevertheless deserve

\footnotetext{
viii Analogues of SAHA bearing either a squaric acid $\mathrm{N}$-hydroxylamine or thio squaric derivatives or methylthioesters derivatives did not display activity below $1 \mu \mathrm{M}$.
} 
screening to generate an alternative starting point for the design of inhibitors with perhaps improved pharmacological properties.

Nevertheless, very few squaric acid N-hydroxylamines amides have been prepared and described until now.[43]

\section{a-Parallel synthesis}

In our ongoing research program aiming at the synthesis of potent inhibitors of zincmetalloproteases based on acidic templates, we investigated the synthesis of squaric acid $\mathrm{N}$-hydroxylamide amides using simple convergent solution synthesis. ${ }^{\text {ix }}$
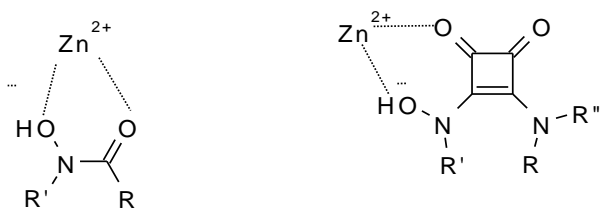

Figure 10. Known binding mode of hydroxamic acid and putative binding mode by squaric acid derivatives $A$ (6-membered zinc chelation model).

The general solution phase method for parallel synthesis of the library members, using squaric acid inputs and amines is described in Scheme 2. Reaction of dibutyl squarate with a series of hydroxylamines gave 3 precursors. A subsequent reaction with various amines gave an array of 200 vinylogous hydroxamic acids.

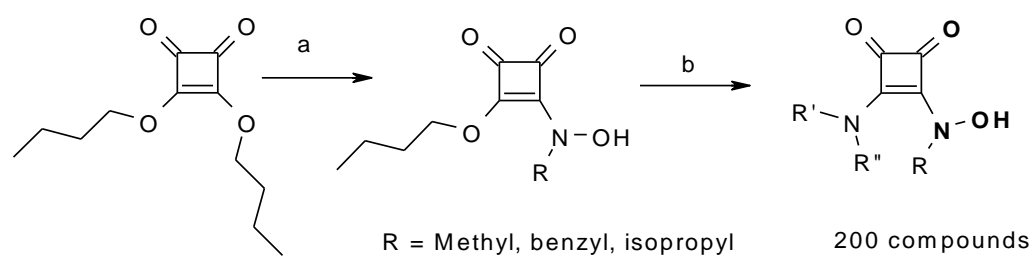

Scheme 2. Reaction conditions : a. N-substituted hydroxylamine hydrochloride, 1.5 equiv., $\mathrm{KOH}$, 1.5 equiv., MeOH, room temp., $5 \mathrm{~h}$ b. amines R'R"NH (1.1 equiv, $16.5 \mu \mathrm{mol}$ ), $\mathrm{MeOH}$, room temp., $5 \mathrm{~h}$.

\section{b-Choice of amines}

Amines were chosen in order to generate a diversity of pharmacophore properties and geometries. Primary and secondary amines were selected. Among the primary

\footnotetext{
${ }^{\text {ix } C h a r t o n, ~ J ., ~ D e p r e z-P o u l a i n, ~ R ., ~ D e p r e z, ~ B . ~ T e t r a h e d r o n ~ L e t t . ~ s u b m i t t e d ~}$
} 
amines (54 inputs, Figure 11), aliphatic amines, aromatic amines (benzylamines, phenethylamines, anilines...), amino-alcohol and amino-acids were incorporated. Among secondary amines (20 inputs, Figure 11), cyclic amines (piperidines, piperazines) and acyclic secondary amines were selected. As explained above, such building-blocks are expected to behave as privileged structures.

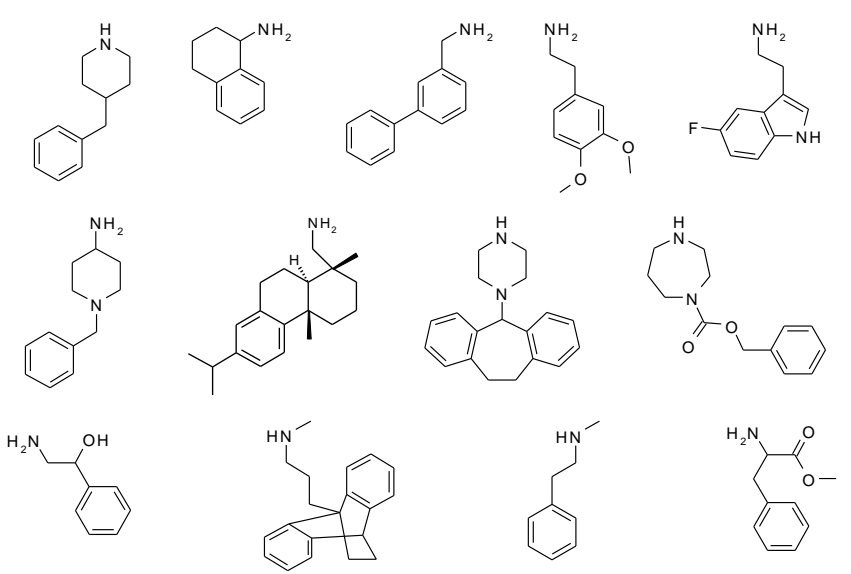

Figure 11: Some prototypal primary and secondary amines of the library.

Each compound was obtained with very good purity in a $15 \mu \mathrm{mol}$ scale suitable for biological screening. Out of the 200 library members, $86 \%$ displayed purity above $80 \%$ and were obtained in very good yield $(75-100 \%)$.

\section{Discussion-Conclusion}

Recent attention has focused on the need to assess the potential for bioavailability problems of potential drug candidates early in the drug discovery cycle. Lipophilicity, hydrophilicity, hydrogen bonding and pKa are likely to be important factor for absorption, transport and excretion of compounds.[44] We compared the initial physico-chemical profile of amines with the final squaric acid derivatives either squaramic acids or squaric acid hydroxamate amides (Figure 12). Interestingly, these compounds differ mainly from amines by $\mathrm{pKa}$ and charge at physiological $\mathrm{pH}$, and the presence of a potentially ZBG.

Using conventional $\mathrm{Zn}$ ligands and this original array of squaramides and squaramic acids we have recently started an in vitro screening campaign on six $\mathrm{Zn}$

\footnotetext{
${ }^{\mathrm{x}}$ For ease of discussion, average values were attributed to initial amine buiding-blocks.
} 
metalloproteases. Inhibitors will be used for the functional exploration of these enzymes in several biological setups.

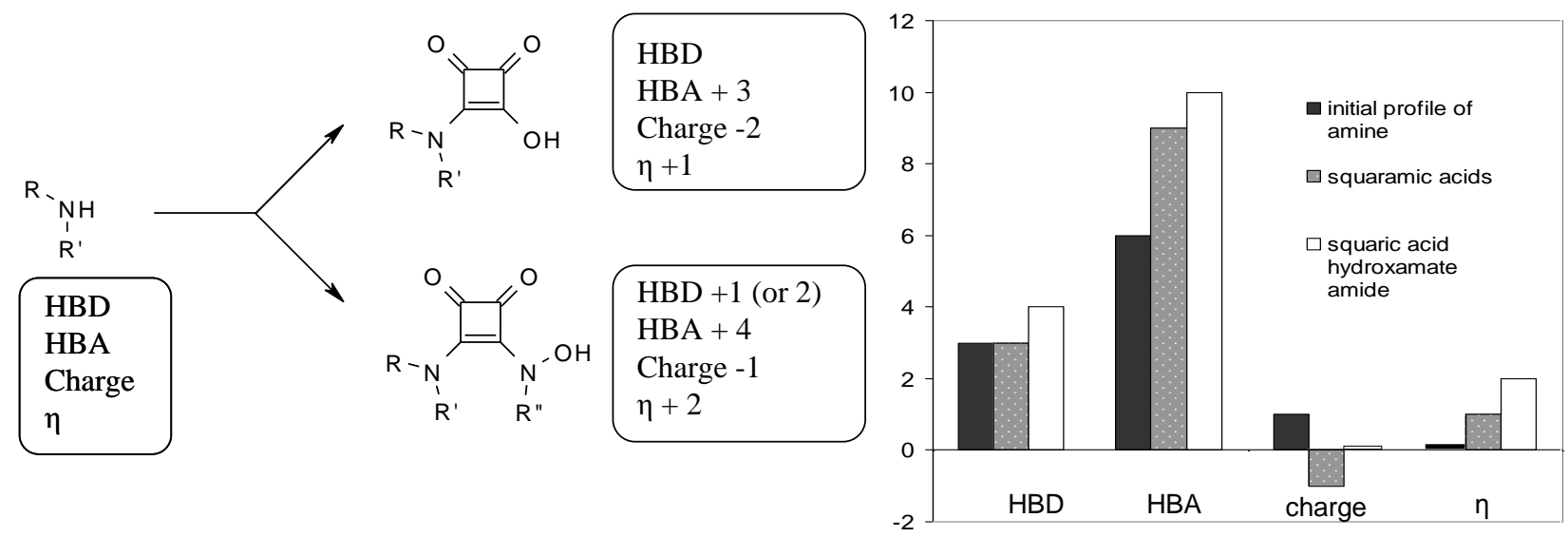

Figure 12: Comparison of the initial physico-chemical profile of amines and squaric acid derivatives ( $\eta$ represents the hapticity of the potential $\mathrm{Zn}$ ligand).

Acknowledgements: We are grateful to the institutions that support our laboratory (Inserm, Université de Lille2 and Institut Pasteur de Lille). Data management was performed using Pipeline Pilot ${ }^{\mathrm{TM}}$ from Scitegic. We thank also the following institutions or companies: CAMPLP and VARIAN.inc. This project was supported by the European Commission - ERDF funds, grant N OBJ2 - 2006/364.1 №302.

\section{References and Notes}

[1] Deprez-Poulain, R. and Deprez, B. Frontiers in Medicinal Chemistry 2006, 3, 653-673.

[2] Nieto, M. J., Philip, A. E., Poupaert, J. H. and McCurdy, C. R. J. Comb. Chem 2005, 7, 258-263.

[3] Horton, D. A., Bourne, G. T. and Smythe, M. L. Chem. Rev. 2003, 103, 893930.

[4] MacLean, D.; Baldwin, J.J.; Ivanov, V.T.; Kato, Y.; Shaw, A.; Schneider, P.; Gordon, E.M. Pure Appl.Chem., 1999, 71, 2349-2365.

[5] (a) Deprez-Poulain, R., Willand, N., Boutillon, C., Nowogrocki, G., Azaroual, N. and Deprez, B. Tetrahedron Lett. 2004, 45, 5287. (b)Willand, N., Beghyn, T., Nowogrocki, G., Gesquiere, J.-C. and Deprez, B. Tetrahedron Lett. 2004, 45, 1051. 
[6] Willand, N., Folleas, B., Boutillon, C., Verbraeken, L., Gesquiere, J.-C., Tartar, A. and Deprez, B. Tetrahedron Lett. 2007, 48, 5007.

[7] Horton, D. A.; Bourne,G. T.; Smythe, M. L. Chem. Rev. 2003, 103, 893-930

[8] Camille G.Wermuth DDT , 2006, 11, 160-164.

[9] Seio, K.; Miyashita, T.; Sato, K.; Sekine, M. Eur. J. Org. Chem. 2005, 51635170

[10] Swartz, L. M.; Howard, L. O. J. Phys. Chem. 1971, 75, 1798-1803.

[11] Terao, H.; Sugawara, T.; Kita, Y.; Kaho, E.; Takeda, S. J. Am. Chem. Soc. 2001, 123, 10468-10474.

[12] Schmidt, A. H. Synthesis 1980, 961-994.

[13] West, R.; Niu, H. Y. J. Am. Chem. Soc. 1963, 85, 2589-2590.

[14] a) Cohen, S.; Lacher, J. R.; Park, J. D. J. Am. Chem. Soc. 1959, 81, 3480. b) Park, J. D.; Cohen, S.; Lacher, J. R. J. Am. Chem. Soc. 1962, 84, 2919-2922. c) Cohen, S.; Cohen S. G. J. Am. Chem. Soc. 1966, 88, 1533-1536.

[15] a) Onaran, M. B.; Comeau, A. B.; Seto, C. T. J. Org. Chem. 2005, 70, $10792-$ 10803. b)Xu, Y.; Yamamoto, N.; Ruiz, D. I.; Kubitz, D. S.; Janda, K. D. Bioorg. Med. Chem. Lett. 2005, 15, 19, $4304-4307$ c) Tevyashova, A.; Sztaricskai, F.; Batta, G.; Herczegh, P.; Jeney, A. Bioorg. Med. Chem. Lett. 2004, 14, 18, 4783-4789. d) Xie J, Comeau, A. B.; Seto, C. T. Org. Lett. 2004, 6, 1, 83-86. e) Porter, J. R.; Archibald, S. C.; Childs, K.; Critchley, D.; Head, J. C.; Linsley, J. M.; Parton, T. A.; Robinson, M. K.; Shock, A.; Taylor, R. J.; Warrellow, G. J.; Alexander, R. P.; Langham, B. Bioorg. Med. Chem. Lett. 2002, 12, 7, 1051-1054.

[16] a) Sato, K.; Seio, K.; Sekine, M. J. Am. Chem. Soc. 2002, 124, 12715-12724.

b) Seio, K.; Miyashita, T.; Sato, K.; Sekine, M. Eur. J. Org. Chem. 2005, 51635170

[17] Hanessian, S.; Vinci, V.; Auzzas, L.; Marzi, M.; Giannini, G. Bioorg. Med. Chem. Lett. 2006, 16, 18, 4784-4787.

[18] Ishida, T.; Shinada, T.; Ohfune, Y. Synthesis 2005, 2723-2729. Ishida, T. ; Shinada, T. ; Ohfune, Y. Tetrahedron Lett. 2005, 46, 311-314.

[19] Kinney, W. A.; Lee, N. E.; Garrison, D.T.; Podlesny, E. J.; Simmonds, Jr. J. T.; Bramlett, D.; Notvest, R. R.; Kowal, D. M.; Tasse, R.P. J. Med. Chem. 1992, 35, 4720-4726. 
[20] Campbell, E. F.; Park, A. K.; Kinney, W. A.; Fengl, R. W.; Liebeskind, L. S. J. Org. Chem. 1995, 60, 1470-1472.

[21] Xie, J.; Comeau, A. B.; Seto, C. T. Org. Lett. 2004, 6, 83-86.

[22] Lee, C. W.; Cao, H.; Ichiyama, K; Rana, T. M. Bioorg. Med. Chem. Lett. 2005, 15, 19, 4243-4246.

[23] a) Butera, J. A.; Antane, M. M.; Antane, S. A.; Argentieri, T. M.; Freeden, C.; Graceffa, R. F.; Hirth, B. H.; Jenkins, D.; Lennox, J. R.; Matelan, E.; Norton, N. W.; Quagliato, D.; Sheldon, J. H.; Spinelli, W.; Warga, D.; Wojdan, A.; Woods, M. J. Med. Chem. 2000, 43, 6, 1187-1202. b) Gilbert, A. M.; Antane, M. M.; Argentieri, T. M.; Butera, J. A.; Francisco, G. D.; Freeden, C.; Gundersen, E. G.; Graceffa, R. F.; Herbst, D.; Hirth, B. H.; Lennox, J. R.; McFarlane, G.; Norton, N. W.; Quagliato, D.; Sheldon, J. H.; Warga, D.; Wojdan, A.; Woods, M. J. Med. Chem. 2000, 43, 6, 1203-1214, c) Butera, J. A.; Jenkins, D. J.; Lennox, J. R.; Sheldon, J. H.; Norton, N. W.; Warga, D.; Argentieri, T.M. Bioorg. Med. Chem. Lett. 2005, 15, 19, 2495-2501.

[24] Chao, J. ; Taveras, A.G.; Chao, J.; Aki, C.; Dwyer, M.; Yu, Y.; Purakkattle, B.; Rindgen, D.; Jakway, J.; Hipkin, W.; Fosetta, J.; Fan, X.; Lundell, D.; Fine, J.; Minnicozzi, M.; Phillips, J.; Merritt, J.B. Bioorg. Med. Chem. Lett. 2007, 17, 3778-3783.

[25] Hajduk, P. J., Bures, M., Praestgaard, J. and Fesik, S. W. J. Med. Chem. 2000, 43, 3443-3447.

[26] Charton, J., Cousaert, N., Bochu, C., Willand, N., Deprez, B. and DeprezPoulain, R. Tetrahedron Lett. 2007, 48, 1479-1483.

[27] (a) Flipo, M., Beghyn, T., Charton, J., Leroux, V. A., Deprez, B. P. and DeprezPoulain, R. F. Bioorg. Med. Chem. 2007, 15, 63-76. (b) Flipo, M., Beghyn, T., Leroux, V., Florent, I., Deprez, B. P. and Deprez-Poulain, R. F. J. Med. Chem. 2007, 50, 1322-1334.

[28] Pirrung, M. C.; Han, H.; Chen, J. J. Org. Chem. 1996, 61, 4527-4531.

[29] Escolano, C., Amat, M. and Bosch, J. Chemistry - A European Journal 2006, 12, 8198-8207.

[30] Newman, D. J., Cragg, G. M. and Snader, K. M. J. Nat. Prod. 2003, 66, 10221037. 
[31] Mason, J. S., Morize, I., Menard, P. R., Cheney, D. L., Hulme, C. and Labaudiniere, R. F. J. Med. Chem. 1999, 42, 3251-3264.

[32] Ortholand, J.-Y. and Ganesan, A. Curr. Opin. Chem. Biol. 2004, 8, 271.

[33] Abbenante, G. and Fairlie, D. P. Med Chem 2005, 1, 71-104.

[34] Supuran, C. T., Casini, A., Mastrolorenzo, A. and Scozzafava, A. Mini Rev. Med. Chem. 2004, 4, 625-632.

[35] Grant, S., Easley, C. and Kirkpatrick, P. Nat. Rev. Drug Discov. 2007, 6, 21.

[36] Wen, S., Carey, K. L., Nakao, Y., Fusetani, N., Packham, G. and Ganesan, A. Org. Lett. 2007, 9, 1105-1108.

[37] a) Pikul, S.; Ohler, N. E.; Ciszewski, G.; Laufersweiler, M. C.; Almstead, N. G.; De, B.; Natchus, M. G.; Hsieh, L. C.; Janusz, M. J.; Peng, S. X.; Branch, T. M.; King, S. L.; Taiwo, Y. O.; Mieling, G. E. J. Med. Chem. 2001, 44, 2499-2502. b) Suzuki, T.; Miyata, N. Curr. Med. Chem. 2005, 12, 2867.

[38] For a recent review on Zinc-binding groups see : Faith E. Jacobsen, J. A. Lewis. Seth. M. Cohen. ChemMedChem 2007, 2, 152-171.

[39] Puerta, D. T., Lewis, J. A. and Cohen, S. M. J. Am. Chem. Soc. 2004, 126, 8388-8389.

[40] Sheppeck, J. E., 2nd, Gilmore, J. L., Tebben, A., Xue, C. B., Liu, R. Q., Decicco, C. P. and Duan, J. J. Bioorg. Med. Chem. Lett. 2007, 17, 2769-2774.

[41] Park, H. and Merz, K. M., Jr. J. Med. Chem 2005, 48, 1630-1637.

[42] Lim, N. C.; Morton, M. D.; Jenkins, H. A.; Bruckner, C. J. Org. Chem. 2003, 68, 9233-9241.

[43] Zinner, G.; Grünefeld, J. Arch. Pharm. (Weinheim), 1985, 318, 977-983.

[44] Martin C.M. J. Med. Chem. 2005, 48, 3164-3170. 